\title{
Investigation of TPP-Chitosomes particles structure and stability as encapsulating agent of cholecalciferol
}

\author{
Aline Sayuri Lima lida1, Karina Novais Luz', Taís Téo Barros-Alexandrino ${ }^{2,3}$, \\ Carmen Sílvia Fávaro-Trindade ${ }^{1}$, Samantha Cristina de Pinho ${ }^{1}$, Odílio Benedito Garrido Assis ${ }^{2}$ and \\ Milena Martelli-Tosi ${ }^{*}$ (D)
}

\begin{abstract}
'Departamento de Engenharia de Alimentos, Faculdade de Zootecnia e Engenharia de Alimentos - FZEA, Universidade de São Paulo - USP, Pirassununga, SP, Brasil

${ }^{2}$ Laboratório Nacional de Nanotecnologia para o Agronegócio, Embrapa Instrumentação, São Carlos, SP, Brasil

${ }^{3}$ Programa de Pós-Graduação em Biotecnologia (PPG-Biotec) da Universidade Federal de São Cartos, UFSCar, São Carlos, SP, Brasil.
\end{abstract}

*mmartelli@usp.br

\begin{abstract}
Tripolyphosphate (TPP)-chitosomes were produced aiming at the encapsulation and conservation of vitamin D3. This hybrid system is made of liposomes, vesicles consisting of phospholipid bilayers, surrounded by chitosan wall ionic-crosslinked with TPP. Chitosan concentrations $\left(2\right.$ and $\left.4 \mathrm{mg} \mathrm{mL}^{-1}\right)$ were tested and the vitamin stability in aqueous dispersions monitored for 49 days. The results confim that D3 remained stable throughout the analyzed period (49 days), whereas the non-encapsulated vitamin totally degrades after the second week of storage. The particle diameters ranged from 0.1 to $5 \mu \mathrm{m}$ with good colloidal stability ( +22 to $+48 \mathrm{mV}$ ), and encapsulation efficiency of $97 \%$. Thermal stability was also improved when using the TPP-chitosomes. The protection performed was attributed to the stable interactions conferred by the phospholipids crosslinking with the chitosan amino groups and a formation of a net of hydrogen bonds established amongst the hydroxyl groups of the interacting compounds as revealed by infrared spectroscopy.
\end{abstract}

Keywords: liposomes, cholecalciferol, lecithin, encapsulation, vitamin stability.

How to cite: Iida, A. S. L., Luz, K. N., Barros-Alexandrino, T. T., Fávaro-Trindade, C. S., Pinho, S. C., Assis, O. B. G., \& Martelli-Tosi, M. (2019). Investigation of TPP-Chitosomes particles structure and stability as encapsulating agent of cholecalciferol. Polímeros: Ciência e Tenologia, 29(4), e2019049. https://doi.org/10.1590/0104-1428.04119

\section{Introduction}

Vitamins are vital substances for the maintenance of human health and metabolic functions. Vitamin D, in particular, has the fundamental physiological property of stabilizing the calcium homeostasis and is also involved in several cellular processes, such as immunology and regulation of gene transcription ${ }^{[1]}$. The American Institute of Medicine, Food and Nutrition Board recommends a daily intake of 10 to $15 \mu \mathrm{g}$ of vitamin D to achieve acceptable levels of serum 25-hydroxyvitamin D [25(OH)D $]^{[2]}$. This recommendation applies to both forms of vitamin-D, namely ergocalciferol (vitamin D2) and cholecalciferol (vitamin D3), which are from vegetal and animal sources, respectively. However, some studies have shown that the administration of vitamin D3 is more effective in increasing serum $25(\mathrm{OH}) \mathrm{D}$ levels than vitamin $\mathrm{D} 2^{[3]}$, either from cutaneous synthesis or through dietary ingestion.

The vitamin D insufficiency in general population is much common than currently reported ${ }^{[4]}$, and the enrichment of food products can be an alternative to ensure the consumption of adequate levels of nutrients ${ }^{[5]}$. Vitamins, however, are sensitive compounds. Heat, light, variation of

$\mathrm{pH}$ and exposure to atmospheric oxygen can accelerate their degradation ${ }^{[6,7]}$, thus requiring appropriate means to increase the stability and preserve properties before consumption.

Encapsulation is one of the strategies to overcome this problem and different materials are described to form protective matrices for vitamins. Gelatin ${ }^{[8]}$, whey protein $^{[9]}$, maize prolamine protein ${ }^{[10]}$, multilamenar liposomes ${ }^{[11]}$, pickering emulsions stabilized by nanofibrillated cellulose ${ }^{[12]}$, and nanostructured lipid carriers ${ }^{[13]}$, have been tested to entrap vitamin D. Among these, the system based on liposomes encapsulation combined with chitosan has been suggested as a suitable approach to protect and achieve intestinal absorption $^{[14]}$.

Conventional liposomes have low resistance to gastric $\mathrm{pH}$ and are very susceptible to enzymatic lysis. The formation of a surrounding polymeric wall, such as chitosan, can improve significantly their stability ${ }^{[15]}$. Chitosan is a cationic polysaccharide consisting of glucosamine units of poly- $(\beta(1 \rightarrow 4)$-2-amino-2-deoxy-D-glucopyranose) largely evaluated as encapsulation matrix of active compounds ${ }^{[16]}$. Chitosan can be formulated into nanoparticles by ionic 
crosslinking, formed between the positively charged amino groups in the chitosan and the negatively charged species of an anionic polymer, such as the sodium tripolyphosphate (TPP). Such process is referred to as ionic gelation and has been successfully applied to encapsulation and delivery of vitamins B9, B12 and $\mathrm{C}^{[17,18]}$.

By forming a stable three-dimensional network, the chitosan-TPP complex is also suitable to coat liposomes by binding to polar heads of lipid bilayers with no alteration in the phospholipids in the vesicles assembling ${ }^{[15,19]}$. In such hybrid system, the release occurred preferentially in an alkaline $\mathrm{pH}$, what provides protection to acid stress.

In the present study, the aim was to prepare and characterize the complexation of chitosan and TPP as liposome protective coating and evaluate the stability of this system in the retention of vitamin D3 in aqueous dispersion over time.

\section{Material and Methods}

\subsection{Material}

Medium molecular weight chitosan (Product 448877, 190,000-310,000 Da with 75\%-85\% deacetylated units), sodium tripolyphosphate (TPP, Product 238503), and cholecalciferol (98\% purity, Product C9756), were all purchased from Sigma-Aldrich (St. Louis, MO, USA). Phospholipon ${ }^{\circledR}$ 90G (Lipoid GmbH, Ludiwgshafen, Germany) and HPLC grade methanol (Merck KGaA, Darmstadt, Germany) were also used.

\subsection{Preparation of Chitosan-TPP particles (Ch-Np) and vitamin loading}

The chitosan nanoparticles (Ch-Np) were synthesized following the ionic gelation method as described by Britto et al. ${ }^{[18]}$. In brief, the process consisted of solubilizing chitosan in $1.0 \mathrm{wt} \%$ acetic acid aqueous solution under moderate stirring for $16 \mathrm{~h}$. Two chitosan concentrations ( $2 \mathrm{mg} \mathrm{mL}^{-1}$ and $4 \mathrm{mg} \mathrm{mL}^{-1}$ ) were prepared and identified as $\mathrm{Ch} 2$ and $\mathrm{Ch} 4$ respectively. Subsequently, a solution of TPP at a concentration of $0.6 \mathrm{~mL} \mathrm{~min}^{-1}$ was added, dropwise with stirring, to the chitosan solutions at a rate of $1.0 \mathrm{~mL} \mathrm{~min}^{-1}$.
The resultant nanoparticles were identified as $\mathrm{Ch} 2-\mathrm{Np}$ and Ch4-Np.

In parallel, $50 \mathrm{mg}$ of vitamin D3 (V) was diluted in $2 \mathrm{~mL}$ of $96 \%$ ethanol and separately added to $48 \mathrm{~mL}$ of each chitosan solution, resulting in final vitamin D3 concentrations of $1 \mathrm{mg} \mathrm{mL}^{-1}$. The dispersion was mixed by an Ultraturrax T18 homogenizer (Ika, USA) for $2 \mathrm{~min}$ (at $13000 \mathrm{rpm}$ ) to ensure physical mixture. Then, the TPP solution $\left(0.6 \mathrm{mg} \mathrm{mL}^{-1}\right)$ was dropped to the mixture at $1.0 \mathrm{~mL} \mathrm{~min}{ }^{-1}$, under magnetic stirring, generating the loaded nanoparticles, named $\mathrm{Ch} 2-\mathrm{Np}-\mathrm{V}$ and $\mathrm{Ch} 4-\mathrm{Np}-\mathrm{V}$. All samples were prepared at room temperature $\left(20-30^{\circ} \mathrm{C}\right)$ and away from light (flasks covered with aluminum foil).

\subsection{Preparation of TPP-Chitosomes (TPP-Ch)}

Phospholipon $^{\circledast}$ (Lipoid 90G, $100 \mathrm{mg}$ ) was weighed, dispersed in $2 \mathrm{~mL}$ of $96 \%$ ethanol, added to $48 \mathrm{~mL}$ of deionized water and mechanically homogenized for $2 \mathrm{~min}$ at $13000 \mathrm{rpm}$ (Ultraturrax T18, Ika, USA) to produce the liposomes. For TPP-chitosome preparation, the dispersion with Phospholipon ${ }^{\circledast}$ was mixed with both chitosan solutions ( 2 and $4 \mathrm{mg} \mathrm{mL}^{-1}$ ) and the TPP added in analogous manner as previous outlined.

For vitamin loading, $50 \mathrm{mg}$ of vitamin D3 was first diluted in $2 \mathrm{~mL}$ of $96 \%$ ethanol and added to $46 \mathrm{~mL}$ of each chitosan solution. Then, $2 \mathrm{~mL}$ of the phospholipid dispersion was added and mechanically homogenized in an Ultraturrax for $2 \mathrm{~min}$. TPP was then dropped to promote crosslinking and vitamin retention into the chitosomes particles (TPP-Ch2-V and TPP-Ch4-V). The final compositions and all samples identification are summarized in Table 1. All samples were prepared at room temperature $\left(20-30{ }^{\circ} \mathrm{C}\right)$ and protected from light.

\subsection{Characterization of particles}

Suspensions of particles (with and without vitamin) were sonicated for $15 \mathrm{~min}$ in the ultrasonic bath (Ultra Cleaner 1400A, Unique, Brazil), in deionized water $(1: 10 \mathrm{v} / \mathrm{v})$, cast on a silicon slides and allowed to dry for $48 \mathrm{~h}$ at room temperature. SEM-FEG images were recorded by a JSM-6701F field emission microscope (JEOL, Japan) with

Table 1. Samples identification according to composition.

\begin{tabular}{lcccc}
\hline \multicolumn{1}{c}{ Sample } & Chitosan $\left(\mathbf{m g} . \mathbf{m L}^{-1}\right)$ & TPP $\left(\mathbf{m g} \cdot \mathbf{m L}^{-1}\right)$ & Vitamin D3 $_{\left(\mathbf{m g} . \mathbf{m L}^{-1}\right)}$ Phospholipon $\left.^{\otimes} \mathbf{m g . m L}^{-1}\right)$ \\
\hline Ch2 & 2 & - & - & - \\
Ch4 & 4 & - & - & - \\
Ch2-Np & 2 & 0.6 & - & - \\
Ch4-Np & 4 & 0.6 & - & - \\
TPP-Ch2 & 2 & 0.6 & - & 2 \\
TPP-Ch4 & 4 & 0.6 & - & 2 \\
Liposomes & - & - & - & 2 \\
Ch2-V & 2 & - & 1 & - \\
Ch4-V & 4 & - & 1 & - \\
Ch2-Np-V & 2 & 0.6 & 1 & - \\
Ch4-Np-V & 4 & 0.6 & 1 & - \\
TPP-Ch2-V & 2 & 0.6 & 1 & 2 \\
TPP-Ch4-V & 2 & 0.6 & 1 & 2 \\
Liposomes-V & 0 & - & 1 & \\
\hline
\end{tabular}


an accelerating voltage of $2 \mathrm{kV}$. Scannings were performed on non-coated surfaces.

The particle size distribution and zeta potential were measured by dynamic light scattering (DLS) in a Zetasizer ZS 3600 (Malvern Instruments, USA). All determinations were carried out in triplicate at $25^{\circ} \mathrm{C}$. The final size distributions were considered as the average of three distinct measurements for each synthesis/group.

The thermal stability of the nanoparticles was studied in a thermogravimetric analyser TGA-Q500 (TA Instruments, USA). The dispersions were freeze-dried and samples of about $10 \mathrm{mg}$ sealed in platinum pans and heated from $20^{\circ} \mathrm{C}$ to $600{ }^{\circ} \mathrm{C}$ (heating rate of $10^{\circ} \mathrm{C} \mathrm{min}^{-1}$ ), under nitrogen atmosphere (gas flow of $60 \mathrm{~cm}^{3} \mathrm{~min}^{-1}$ ). Mass changes were continuously recorded as a function of temperature.

Attenuated total reflection Fourier-Transform Infrared spectra (ATR-FTIR) were recorded on IR Prestige-21 (Shimadzu, Kyoto, Japan), in absorbance mode (resolution of $2 \mathrm{~cm}^{-1}$, spectral region of $4000-400 \mathrm{~cm}^{-1}$ ), over 40 consecutive scans. Three spectra were acquired from three freeze-dried sample of each formulation. The average spectra were constructed using the OMNIC ${ }^{\text {TM }}$ Software (Thermo Fisher Scientific, USA).

\subsection{Vitamin quantification and encapsulation efficiency}

The amount of the vitamin D3 retained in the suspensions was quantified according to Staffas and $\mathrm{Nyman}^{[19]}$. An aliquot of $0.5 \mathrm{~g}$ of each sample was mixed with $10 \mathrm{~mL}$ of HPLC grade methanol, vortexed and placed in an ultrasonic bath for $5 \mathrm{~min}$, followed by centrifugation for $5 \mathrm{~min}$ at $5000 \mathrm{rpm}$ (Eppendorf AG, Germany) at $10^{\circ} \mathrm{C}$. After centrifugation, the supernatants were filtered through $0.45 \mu \mathrm{m}$ membrane filter (Millipore Corp., USA) and injected into an HPLC system (Prominence Modular, Shimadzu, Japan) equipped with a C18 column (Merck, $4.6 \mathrm{~mm} \times 250 \mathrm{~mm}$ ) and an inline degasser (DGU-20A5, Shimadzu, Japan). Methanol-acetonitrile $(90: 10 \mathrm{v} / \mathrm{v})$ was used as the mobile phase at a flow rate of $1 \mathrm{~mL} \mathrm{~min}{ }^{-1}$, and the column heated to $35^{\circ} \mathrm{C}$. The analytical curve was generated by injection of vitamin D3 at different concentrations and the vitamin stability measured every 7 days over a 49 days period. The suspensions were stored in $50 \mathrm{~mL}$ Falcon ${ }^{\circledR}$ conical tubes in the refrigerator at $4{ }^{\circ} \mathrm{C}$ and protected from light.

Encapsulation efficiency (EE) was calculated as the difference between the amount of added vitamin D3 in the particle suspension $\left[\mathrm{VitD}_{3}\right]_{A D D E D}$ and the amount of vitamin D3 quantified in the supernatant $\left[\mathrm{VitD}_{3}\right]_{\text {SUPERNATANT }}$ after centrifugation ( $5 \mathrm{~mL}$ for $10 \mathrm{~min}$ at $13000 \mathrm{rpm}$ ), according to the Equation 1.

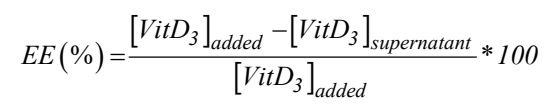

\section{Results and Discussions}

\subsection{Nanoparticles characterization}

Figure 1 provides the SEM-FEG micrographs of the empty systems and vitamin D3 loaded particles. It is generally possible to visualize agglomeration of vitamin D3 on the substrate, in irregular dark stains around the liposomes or as isolated circular patterns in the presence of chitosan. This aggregation occurs due to the lipophilic nature of the cholecalciferol molecules (not soluble in water), arranging them as a circular phase when in aqueous suspension, which stands out as contrasted spots on the dried surface. Dark spots observed in the center of loaded nanoparticles (Ch2-V and Ch4-V) are problably due to thermal degradation of unstable organic compounds during the electron beam exposure.

For non-load chitosan nanoparticles predominates the circular shape in varying dimensions. In the presence of phospholipids, the interaction with TPP-Ch suspension generates smaller particles in irregular shapes and distribution. When the vitamin is added, the surface tension of the particles changes, affecting the colloidal equilibrium, resulting in a reduction of the interaction between the compounds.

The resulted particles are not very well defined with evident aggregation of the smaller ones in large granules, which is clearly observed to TPP-Ch-V systems (Figure 1).

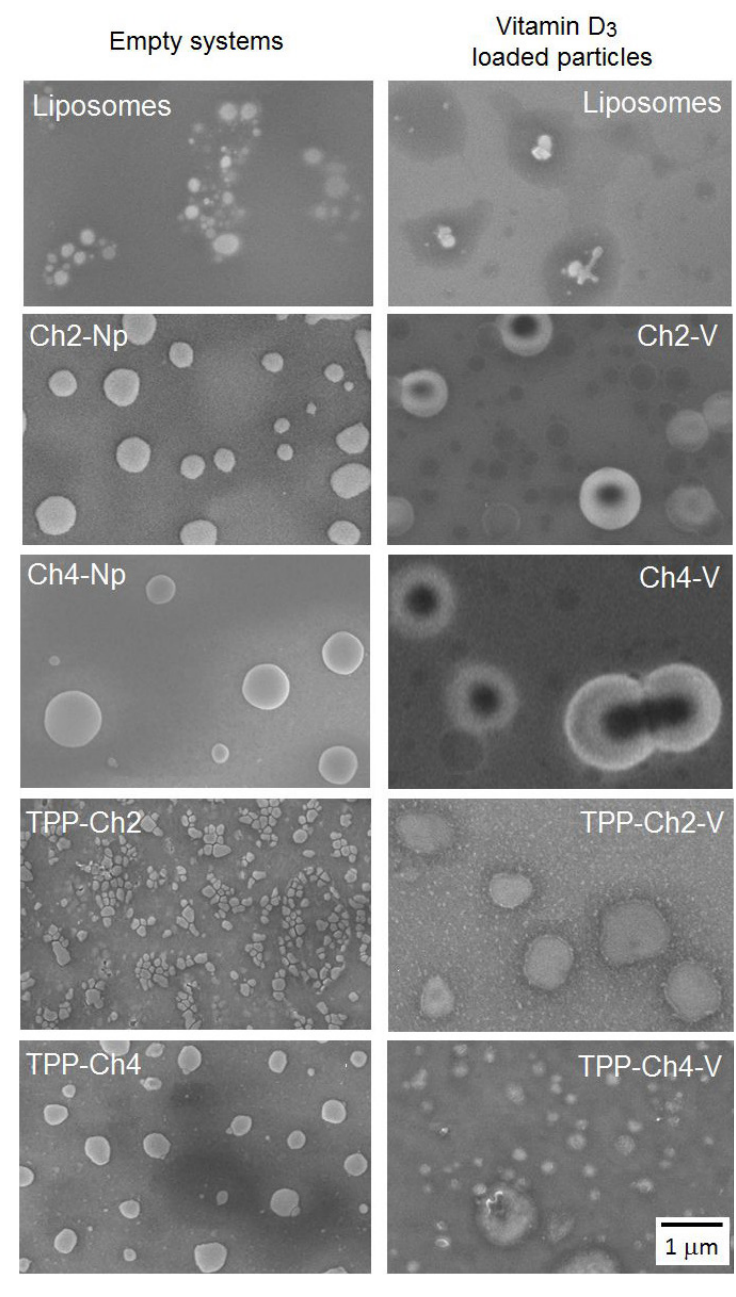

Figure 1. Photomicrographs of empty and vitamin D3 load systems: liposomes, according to adopted identification as displayed in Table 1 . The inserted bar correspond to $1 \mu \mathrm{m}$ for all images. 
These characteristics are confirmed by the size distribution profiles as obtained in the zetasizer equipment (Figure 2). The processed nanoparticles without vitamin have all monodispersed distribution (Figure 2A). Liposome formation has the smallest average size, $32.7 \mathrm{~nm}$, with narrowest size-distribution associated to a slight negative zeta potential
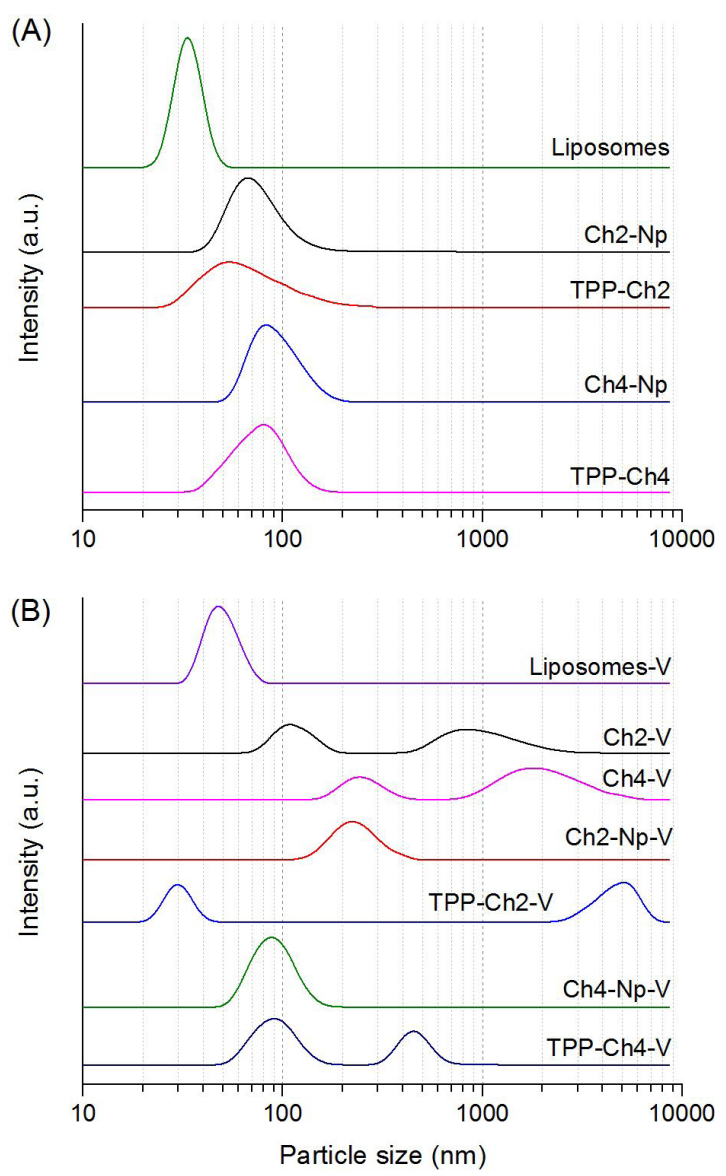

Figure 2. Particle size distributions of (A) empty and (B) vitamin D3 loaded-systems, as acquired from the Zetasizer (each curve represents the average of three measurements). of $-0.8 \mathrm{mV}$. The quasi-neutrality of the liposomes indicates a stability of the three dimensional structure. The liposomes are composed of neutral lipids having one phosphatidyl group and one choline group in their molecules. According to the model presented by Makino et al. ${ }^{[20]}$, the charge neutrality in the formed three dimensional structure resulted from the lipid molecules arranged in such a way that the neutral hydrophilic groups are on the particle surface. When loaded, the zeta potential is enhanced to $-3 \mathrm{mV}$, indicating changes in the liposome dipole configuration due to the vitamin interaction with the head group region (internal cavity).

The different concentrations of chitosan introduce slight changes in the particle sizes. Average dimensions of $68 \mathrm{~nm}(\mathrm{Ch} 2-\mathrm{Np})$ and $53 \mathrm{~nm}$ (TPP-Ch2) were measured for the concentration of $2 \mathrm{mg} \mathrm{mL}^{-1} .78 \mathrm{~nm}$ was the average size recorded for both $\mathrm{Ch} 4-\mathrm{Np}$ and $\mathrm{TPP}-\mathrm{Ch} 4$ when reacting $4 \mathrm{mg} \mathrm{mL}^{-1}$ of chitosan. Zeta potential values were also preserved (+40 mV for Ch2-Np and $+48 \mathrm{mV}$ for Ch4-Np).

When vitamin is added (Ch-Np-V and TPP-Ch-V series), the ionic formation of particles is disturbed in some way that the distribution assumes a bimodal profile with large aggregates as confirmed by microscopic analyses. Averages sizes as low as $28 \mathrm{~nm}$ and as large as $5560 \mathrm{~nm}$ were found for TPP-Ch2-V samples. Distributions centered at $91 \mathrm{~nm}$ and $459 \mathrm{~nm}$ are read for TPP-Ch4-V. In these, Zeta potential ranges from $+23 \mathrm{mV}$ to $+38 \mathrm{mV}$ suggesting reasonable to good stability of the loaded carriers ${ }^{[21]}$. Numerical data are summarized in Table 2.

\subsection{Stability of the capsules}

The instability index describes the portion of the samples that were separated by centrifugal forces and expressed by a normalized position of the flocculated/supernatant boundary. The higher the index value, the lower is the colloidal dispersion stability. According to measurements as obtained by the LUMiSizer (Table 2), the instability of empty particles increases as the chitosan concentration increases $(\mathrm{Ch} 2-\mathrm{Np}=0.22$ and $\mathrm{Ch} 4-\mathrm{Np}=0.49)$. However, no significant difference was observed when these capsules are vitamin loaded (Ch2-V and Ch4-V). Both indexes were relatively small ( 0.02 and 0.01 respectively), which would mean high stability of this system. It is noteworthy that

Table 2. Zeta potential, particle size, instability index and encapsulation efficiency (EE) of the suspensions containing chitosan-TPP micro/nanoparticles at two chitosan concentrations: 2 and $4 \mathrm{mg} \mathrm{mL}^{-1}(\mathrm{Ch} 2$ and $\mathrm{Ch} 4)$.

\begin{tabular}{lccccc}
\hline \multicolumn{1}{c}{ Sample } & \multicolumn{2}{c}{ Particle size (nm) } & & \\
\hline Ziposomes & $-0.80 \pm 0.03^{\mathrm{a}}$ & $32.7 \pm 11.2$ & Peak 2 & Instability index & EE (\%) \\
Liposomes-V & $-3.02 \pm 0.05^{\mathrm{b}}$ & $44 \pm 16.6$ & - & $*$ & - \\
Ch2-V & $+44 \pm 1^{\mathrm{c}}$ & $106 \pm 34.5$ & $825 \pm 349$ & $0.02 \pm 0.00$ & $5 \pm 1^{\mathrm{a}}$ \\
Ch2-Np & $+40 \pm 3^{\mathrm{c}, \mathrm{e}}$ & $68.1 \pm 34.8$ & & $0.22 \pm 0.02$ & - \\
Ch2-Np-V & $+28 \pm 3^{\mathrm{f}}$ & $220 \pm 93.5$ & - & $0.63 \pm 0.06$ & - \\
TPP-Ch2 & $+26 \pm 4^{\mathrm{f}}$ & $53.8 \pm 40.7$ & - & $0.83 \pm 0.01$ & $95 \pm 2^{\mathrm{c}}$ \\
TPP-Ch2-V & $+23 \pm 4^{\mathrm{f}}$ & $28.2 \pm 5.64$ & $5560 \pm 1358$ & $0.57 \pm 0.05$ & - \\
Ch4-V & $+46 \pm 1^{\mathrm{e}}$ & $225 \pm 83.6$ & $1720 \pm 1081$ & $0.01 \pm 0.00$ & $97 \pm 1^{\mathrm{c}}$ \\
Ch4-Np & $+48 \pm 3^{\mathrm{e}}$ & $78.8 \pm 38.7$ & - & $0.49 \pm 0.24$ & - \\
Ch4-Np-V & $+38 \pm 2^{\mathrm{c}}$ & $91.3 \pm 31.8$ & - & $0.11 \pm 0.01$ & $75 \pm 10^{\mathrm{b}}$ \\
TPP-Ch4 & $+22 \pm 2^{\mathrm{f}}$ & $78.8 \pm 34.8$ & - & $0.84 \pm 0.01$ & - \\
TPP-Ch4-V & $+35 \pm 1^{\mathrm{g}}$ & $91.3 \pm 36.8$ & $459 \pm 119$ & $0.29 \pm 0.10$ & $97 \pm 1^{\mathrm{c}}$ \\
\hline
\end{tabular}

*Samples were very translucent. Means with different superscript letters in the same column are statistically different at $\mathrm{p}<0.05$. 
these samples were translucent, thus the response generated by the LUMiSizer may have underestimated the results.

In general, the results evidenced that the vitamins encapsulated with $4 \mathrm{mg} \mathrm{mL}^{-1}$ of chitosan were more stable than those with $2 \mathrm{mg} \mathrm{mL}^{-1}$, namely by electrostatic repulsion between the particles. A higher concentration of chitosan favours the presence of residual charges on particles surface (as confirmed by zeta potential measurements). When submitted to centrifugation, the repulsive forces made the particles more difficult to agglomerate, leading to a slower flocculation.

The highest instability was verified to suspensions containing phospholipids (TPP-Ch2 and TPP-Ch4), with indexes of 0.83 and 0.84 , respectively. Both formulations resulted in the smallest particles in size with low zeta potential (little repulsion forces). The particles could eventually aggregate contributing to a condition of continuity of the matrix, which is interpreted as low stability of this system.

\subsection{Vitamin D3 encapsulation efficiency in Ch-Np and TPP-chitosomes}

Values of vitamin encapsulation efficiency (EE), as estimated by centrifuging the dispersion and quantified as the percentage of vitamin in the sediment, are also listed in Table 2. Chitosan-TPP nanoparticles are able to retain 95\% of free vitamin in the Ch2-Np-V system and $75 \%$ when the concentration of chitosan is doubled (Ch4-Np-V). In the conjugated liposome system, the efficiency is even greater: $97 \%$ are entrapped in both formulations (TPP-Ch2-V and TPP-Ch4-V). These results were higher than those encountered by Chaves et al. ${ }^{[11]}$, which encountered the EE of D3 in liposomes, produced by proliposomes hydration, of about $91 \%$ during the 42 days of storage. In other systems, the EE was $52 \%$ when D3 was encapsulated using zein nanoparticles, and was greatly improved to $88 \%$ when these particles were coated with carboxymethyl chitosan ${ }^{[10]}$. Therefore, the TPP-Ch system was effective on the entrapement of D3.

Concerning the vitamin degradation in aqueous medium, the Figure 3 shows the temporal evolution of concentrations during storage at room temperature (1 to 49 days), in encapsulated conditions. As reference, dispersion of free-vitamin (non-encapsulated), identified as VitD3 was also essayed. The low stability of VitD3 in suspension is evident, with pronounced variation of concentration over time, reaching almost zero at the end of the first week in a nonlinear fashion.

Vitamin physically trapped by chitosan $(\mathrm{Chx}-\mathrm{V})$ also follows an exponential decay but not with such a marked loss. The decrease in concentrations in these samples is more accentuated during the first 28 days, stabilizing onwards. In this period, the average vitamin concentration dropped to $22 \%$ in $\mathrm{Ch} 2-\mathrm{V}$ nanoparticles and to approximately $18 \%$ for Ch4-V. Similar behaviour is shown by the loaded nanoparticles when synthetized by chitosan-TPP crosslinking (Ch2-Np-V and Ch4-Np-V). In these samples however, the vitamin degradation is less pronounced over time, indicating some protection conferred when the encapsulation matrix is assembled by ionic interaction, independent of the chitosan concentration.

The vitamin D3 deterioration in such exponential decay model fits a pseudo first-order kinetics since as the time increases, the rate of loss also increases ${ }^{[22]}$. The better description for this behaviour can be mathematically expressed by the Weibull model as $\mathrm{Ct} / \mathrm{Co}=\exp \left(-\mathrm{kt}^{\mathrm{n}}\right)$, where $\mathrm{Ct}$ and $\mathrm{Co}$ are the momentary and initial concentration of the vitamin and $\left(-\mathrm{kt}^{\mathrm{n}}\right)$ express, in module, the rate of reaction, i.e., how fast the concentration curve drops with time.

Conversely, for the TPP-chitosomes particles (TPP-Ch2-V and TPP-Ch4-V), there were no significant vitamin losses during storage. In these systems the temporal variation of concentration can be adequately adjusted to a linear fit $\left(\mathrm{t}^{\mathrm{n}}=1\right)$, indicating good stability with minimal reduction in concentration over time. Such indicates that liposomes grafted with TPP-chitosan nanoparticles can lead to great encapsulation efficiency, reducing potential degradations.

\subsection{Thermal decomposition}

The thermal stability of the neat components is compared in the thermograms of Figure 4, according to TG analyses. The initial loss of mass of Phospholipon ${ }^{\circledR}$ is recorded at $120^{\circ} \mathrm{C}$ due to removal of the few absorbed moisture in its structure (approximately $3 \%$ ). The second event was observed between $236^{\circ} \mathrm{C}$ and $307^{\circ} \mathrm{C}$ and assigned to the decomposition of the residual proteins present in the sample, in which around $17 \%$ of the total mass was lost (residual mass of $80 \%$ ). The most severe degradation occurs in the sequence, resulting in an accentuated reduction to $12 \%$ of original mass at the end of
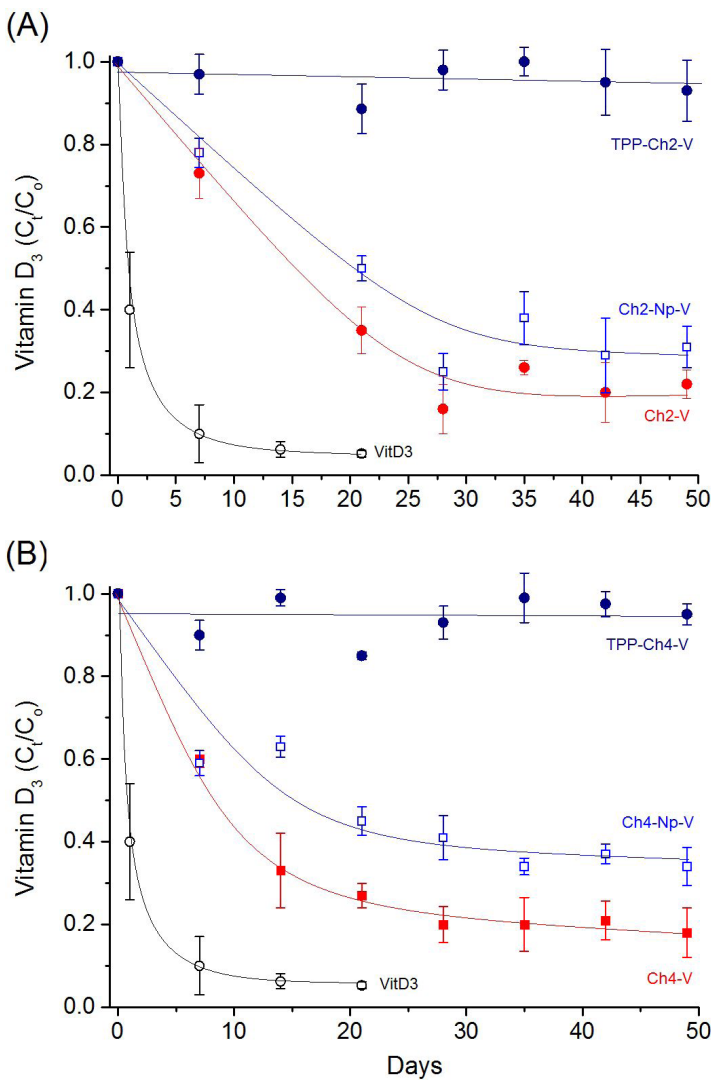

Figure 3. Evolutions of vitamin D3 over 49 days of storage. VitD3 stands for free-vitam-in dispersion (non-encapsulated). For comparison, results were disposed as (A) and (B) according to the chitosan concentration: $2 \mathrm{mg} \mathrm{mL}^{-1}$ and $4 \mathrm{mg} \mathrm{mL}^{-1}$, respectively. $\mathrm{Ct}$ and $\mathrm{Co}$ are the concentration at certain time $\mathrm{t}$ and initially, respectively. Samples identifications according to composition displayed in Table 1. 
the event at $358^{\circ} \mathrm{C}$. The decomposition at this temperature may be attributed to de degradation of the phospholipids ${ }^{[23]}$. From this temperature on the long tail reflects the formation of carbon dioxide and other volatile substances.

Chitosan shows a three-phase decomposition. The first at $87{ }^{\circ} \mathrm{C}$ corresponds to the removal of physically and chemically bonded water $(12 \%)$. The second and more intense, starting at around $250{ }^{\circ} \mathrm{C}$, is related to oxidative backbone degradation mainly to the destruction of amine groups. A third event, from $310^{\circ} \mathrm{C}$, leads to a continuous processes of formation of water, $\mathrm{CO}$, and $\mathrm{CH}_{4}$ followed by depolymerisation and decarbonylation until complete pyrolitic decomposition ${ }^{[24]}$. The vitamin D3, in turn, is the one with the lowest thermal stability. The vitamin is thermally stable until $200^{\circ} \mathrm{C}$ and has a unique event of total mass loss (100\% degradation). No water desorption is recorded due to the hydrophobic nature of this compound.

For the suspensions prepared in the present study, the thermal degradation profiles are shown in Figure 5. In all samples predominates the typical appearance of chitosan degradation (Figure 4) with similar three distinct main events. The initial one (between $40{ }^{\circ} \mathrm{C}$ to $100{ }^{\circ} \mathrm{C}$ ) corresponds to water evaporation with loss of mass varying from 5 to $12 \%$ according to the encapsulation formulation. The second event,

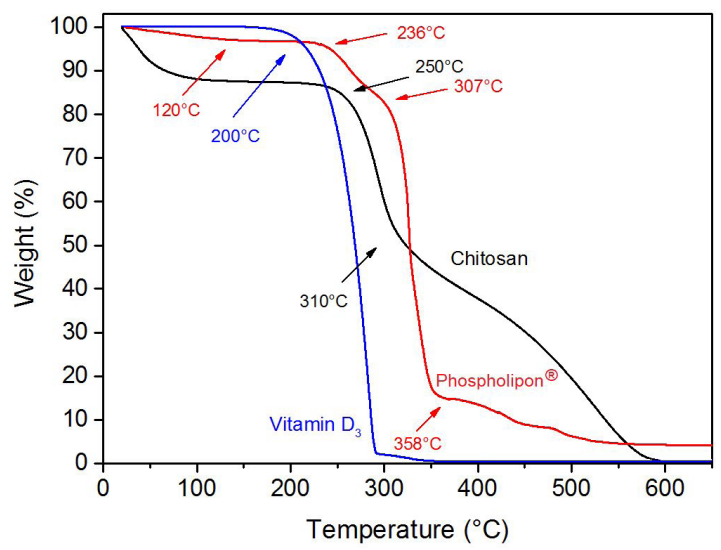

Figure 4. Mass loss as a function of the temperature of the pure components: Phospholipon ${ }^{\circledR}$, vitamin D3 and chitosan.

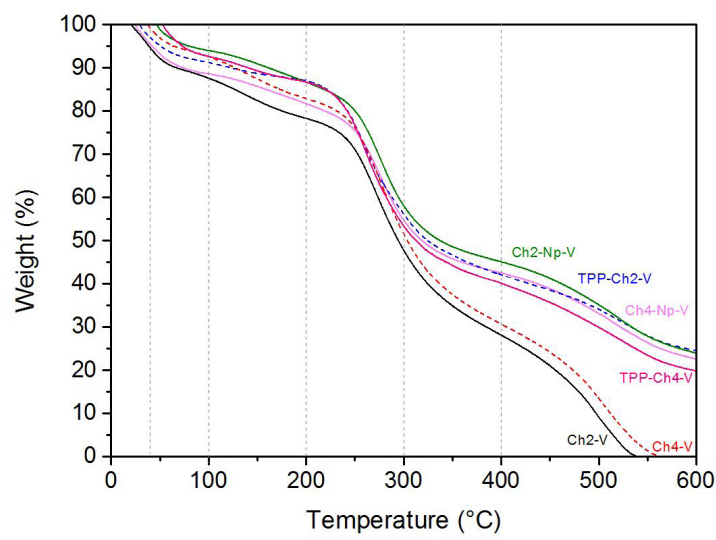

Figure 5. Mass loss as a function of the temperature of vitamin D3-loaded systems: Ch2-Np-V, TPP-Ch2-V, Ch4-Np-V and TPP-Ch4-V, as composition described in Table 1. observed to start above $200{ }^{\circ} \mathrm{C}$, is probably related to the decomposition of the acetylated and deacetylated units of the chitosan structure. The third event ranging from $300^{\circ} \mathrm{C}$ to $400{ }^{\circ} \mathrm{C}$, is related to polymeric structure degradation e vitamin decomposition.

From the curves of Figure 5 is obvious the enhancing of stability introduced by the tripolyphosphate crosslinking. Two distinct groups of samples may be identified: one with an intense decomposition at temperatures above $300^{\circ} \mathrm{C}$, corresponding to vitamin physical entrapped by chitosan (non-cross-linked Chx-V samples), and that with a proportional higher stability, corresponding to TPP cross-linked systems (Chx-Np-V and TPP-Chx-V particles). By $400{ }^{\circ} \mathrm{C}$, the residual mass is approximately $43 \%$ for cross-linked samples while it was found to be as low as $18 \%$ for vitamin samples entrapped only by chitosan. Above this temperature, all samples undergo decarbonylation and pyrolitic decomposition in a more marked way non-crosslinked samples.

\subsection{ATR-FTIR}
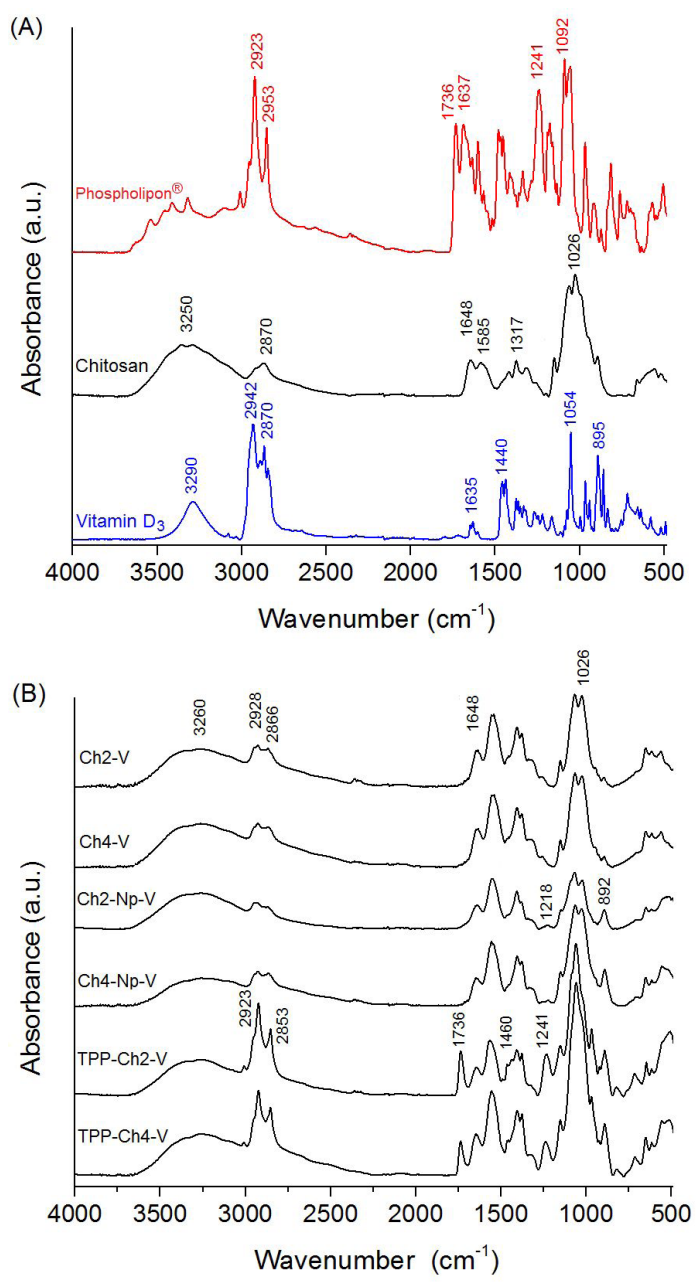

Figure 6. ATR-FTIR of (A) the pure components: Phospholipon ${ }^{\circledR}$, chitosan, vitamin D3 and (B) vitamin D3-loaded systems: Ch2-V, Ch2-Np-V, TPP-Ch2-V, Ch4-V, Ch4-Np-V andTPP-Ch4-V, as described in Table 1. 
Valuable qualitative information about the particle chemical structures can be obtained by Infrared spectroscopy. The FTIR spectra for the neat components (chitosan, Phospholipon ${ }^{\circledR}$ and vitamin D3) are presented in Figure 6A and for the formed particles, displayed in Figure 6B.

All samples present two main spectral ranges: a broad band between 3600 and $2500 \mathrm{~cm}^{-1}$ and a strong absorption region between 1800 and $400 \mathrm{~cm}^{-1}$, both characteristic of amine groups (proteins) and polysaccharide structures. The broad band between $3600-3000 \mathrm{~cm}^{-1}$ is assigned to $\mathrm{O}-\mathrm{H}$ and N-H groups stretching. The bands centred at 3000 and $2700 \mathrm{~cm}^{-1}$ may be attributed to the symmetric and asymmetric $-\mathrm{CH}$ group stretching in the glucosamine ring, which is a typical polysaccharide vibration.

The characteristic spectrum of the phospholipids is typical of phospholipid materials ${ }^{[25]}$. The absorbance bands at 2923 and $2853 \mathrm{~cm}^{-1}$ are related to the alkane groups stretching. The band at $1736 \mathrm{~cm}^{-1}$, has been assigned to the carbonyl stretching vibration band $\mathrm{C}=\mathrm{O}$ of saturated aliphatic ester, which is located between the hydrophilic tails and hydrophobic head groups in the phospholipid molecule ${ }^{[26]}$. The peaks around $1637 \mathrm{~cm}^{-1}$ are largely due to a combination of stretching and scissoring vibrations from $\mathrm{C}=\mathrm{O}, \mathrm{C}=\mathrm{C}$ and $\mathrm{N}=\mathrm{C}$. Asymmetric and symmetric stretching of $\mathrm{PO}_{2}$ is identified as bands at 1241 and $1092 \mathrm{~cm}^{-1}$, respectively ${ }^{[25,27]}$.

Neat chitosan presented typical polysaccharide spectrum with a broad $\mathrm{O}-\mathrm{H}$ groups stretching band near $3250 \mathrm{~cm}^{-1}$. A low intensity band centred at $2870 \mathrm{~cm}^{-1}$ arose from the axial deformation of $\mathrm{C}-\mathrm{H}$ from $\mathrm{CH} 2$ and $\mathrm{CH}_{3}$ groups from the glucosamine unit in the chitosan structure. A clear doublet at $1648 \mathrm{~cm}^{-1}$ was attributed to the $\mathrm{C} 2$ position in the $\mathrm{NH}_{2}$ group of amino. The peak signals at $1585 \mathrm{~cm}^{-1}$ correspond to the NH bending of the amide II in vibrational mode. A medium intensity vibration at $1317 \mathrm{~cm}^{-1}$ is characteristic of $-\mathrm{OH},-\mathrm{NH}_{2}$ or $-\mathrm{CO}$ groups. The more intense vibrations at $1026 \mathrm{~cm}^{-1}$ are associated to $-\mathrm{C}-\mathrm{O}-\mathrm{C}$ - stretching in the glycosidic linkage.

Bands observed in the spectrum of vitamin D3 can be identified as the stretching of hydrogen bond $\mathrm{O}-\mathrm{H}$ at $3290 \mathrm{~cm}^{-1}$ and the alkyl $\mathrm{C}-\mathrm{H}$ vibration in the doublet at $2942 \mathrm{~cm}^{-1}$ and $2870 \mathrm{~cm}^{-1}$. Absorbance bands from $\mathrm{C}=\mathrm{O}$ stretching at 1635 and $1440 \mathrm{~cm}^{-1}, \mathrm{C}-\mathrm{O}$ group at $1054 \mathrm{~cm}^{-1}$ and $\mathrm{CH}_{2}$ group at $895 \mathrm{~cm}^{-1}$ are assigned. Other bands are related to several $\mathrm{C}-\mathrm{H}$ bendings in the cholecalciferol structure ${ }^{[28]}$.

In the particle spectra (Figure 6B), the main absorbance bands came from the chitosan structural absorbances. For chitosan-vitamin D entrapment ( $\mathrm{Chx}-\mathrm{V}$ system), the broad band, related to $\mathrm{O}-\mathrm{H}$ groups, has a shift to maximum at $3269 \mathrm{~cm}^{-1}$, differently from chitosan and vitamin D3 (peaks at 3250 and at $3290 \mathrm{~cm}^{-1}$ respectively), indicating hydrogenic bonds between the hydroxyl groups in chitosan with vitamin D3 ${ }^{[29]}$. Peaks at 2928 and $2866 \mathrm{~cm}^{-1}$, despite low intensities, are visible and associated to non-bonded alkyl $\mathrm{C}-\mathrm{H}$ vibration from vitamin D3. The vibrations peaks in the amide region (between 1648 and $1026 \mathrm{~cm}^{-1}$ ) had obvious shifts in all formulations suggesting the participation of $-\mathrm{NH}_{2}$ groups of chitosan in electrostatic interactions.

The electrostatic interaction between the positively charged amino groups of chitosan and the negatively charged counter-ions of sodium tripolysophosphate (TPP) is the main mechanism of particle formation. In these cross-linked particles (Chx-Np-V and TPP-Chx-V), the main differences in the FTIR spectra, according to Martins et al. ${ }^{[30]}$ refers to weak band at $1218 \mathrm{~cm}^{-1}$ assigned to PO stretching and a band at $892 \mathrm{~cm}^{-1}$ attributed to P-O-P asymmetric stretching. A shoulder around $1460 \mathrm{~cm}^{-1}$ is also considered as arising from the cross-linked amine vibrations ${ }^{[31]}$.

In the samples containing phospholipids (TPP-Chx-V), some peaks can be easy identified, as those related to the alkane groups (2923 and $\left.2853 \mathrm{~cm}^{-1}\right) ; 1736(\mathrm{C}=\mathrm{O}$ stretching from aliphatic ester), $1241 \mathrm{~cm}^{-1}$ ( $\mathrm{PO}_{2}$ stretching) and several other $\mathrm{CH}$ vibrations of saturated and unsaturated carbon atoms at around these peaks. The PO vibration (at $1218 \mathrm{~cm}^{-1}$ ) characteristic of the TPP crosslinking is overlapped in this system by a more intense absorption at $1241 \mathrm{~cm}^{-1}$ for the phospholipids. The intense peak at $1154 \mathrm{~cm}^{-1}$ corresponds to entrapped vitamin D3 vibrations. In all crosslinked samples the peak at $892 \mathrm{~cm}^{-1}$ increases in intensity indicating the formation of a strong net of hydrogen bonds between the hydroxyl groups amongst the interacting compounds.

\section{Conclusions}

Chitosan-based micro/nanoparticles are successfully produced by ionic gelation and can be adequately applied to the encapsulation of vitamin D3. The formed structures have zeta potential between +22 to $+48 \mathrm{mV}$, with variable diameters but not exceeding $225 \mathrm{~nm}$ for load particles. Significant reduction of vitamin degradation in aqueous suspension and under thermal conditions can be attained by entrapping vitamin into liposomes and underwent subsequent formation of a coating with TPP-chitosan complex. Therefore, these systems were were more effective to protect vitamin D3 from time storage than the chitosan-TPP nanoparticles. The infrared spectral analyses suggest good interaction between compounds by establishing an extensive intermolecular interaction. Electrostatic interaction occurs in the majority of amine groups present in chitosan with a formation of a three-dimensional net of hydrogen bonds amongst the hydroxyl groups of the others interacting compounds.. In conclusion, the present study sheds some lights in understanding the formation of liposomes/TPP-chitosan encapsulation system and testifies its efficiency in preserving entrapped lipophilic compounds, such as vitamin D3.

\section{Acknowledgements}

This study was supported by the São Paulo Research Foundation - FAPESP (grant number 2016/18788-1), SiSNano (MCT) and Rede AgroNano (Embrapa). The authors gratefully acknowledge the University of São Paulo for the fellowships granted to Aline S. L. Iida and Karina N. Luz, and the Coordination for the Improvement of Higher Education Personnel (CAPES) for the doctoral fellowships of Taís T. Barros-Alexandrino.

\section{References}

1. Bouillon, R., Okamura, W. H., \& Norman, A. W. (1995). Structure-function-relationships in the vitamin-D endocrine system. Endocrine Reviews, 16(2), 200-257. http://dx.doi. org/10.1210/edrv-16-2-200. PMid:7781594.

2. Ross, A. C., Taylor, C. L., Yaktine, A. L., \& Del Valle, H. B. (2010). Dietary reference intakes for Calcium and Vitamin D. Washington: National Academy Press. Retrieved in 2019, August 9, from https://www.ncbi.nlm.nih.gov/books/NBK56070/ 
3. Trang, H. M., Cole, D. E. C., Rubin, L. A., Pierratos, A., Siu, S., \& Vieth, R. (1998). Evidence that vitamin D-3 increases serum 25-hydroxyvitamin D more efficiently than does vitamin D-2. The American Journal of Clinical Nutrition, 68(4), 854858. http://dx.doi.org/10.1093/ajen/68.4.854. PMid:9771862.

4. Holick, M. F., \& Chen, T. C. (2008). Vitamin D deficiency: a worldwide problem with health consequences. The American Journal of Clinical Nutrition, 87(4), 1080S-1086S. http:// dx.doi.org/10.1093/ajcn/87.4.1080S. PMid:18400738.

5. Calvo, M. S., \& Whiting, S. J. (2013). Survey of current vitamin $\mathrm{D}$ food fortification practices in the United States and Canada. The Journal of Steroid Biochemistry and Molecular Biology, 136, 211-213. http://dx.doi.org/10.1016/j.jsbmb.2012.09.034. PMid:23104118

6. deMan, J. M. (1999). Principles of food chemistry (3rd ed.). Gaithersburg: Aspen Publishers. http://dx.doi.org/10.1007/9781-4614-6390-0.

7. Paucar, O. C., Tulini, F. L., Thomazini, M., Balieiro, J. C. C., Pallone, E., \& Favaro-Trindade, C. S. (2016). Production by spray chilling and characterization of solid lipid microparticles loaded with vitamin D-3. Food and Bioproducts Processing, 100, 344-350. http://dx.doi.org/10.1016/j.fbp.2016.08.006.

8. Jannasari, N., Fathi, M., Moshtaghian, S. J., \& Abbaspourrad, A. (2019). Microencapsulation of vitamin D using gelatin and cress seed mucilage: Production, characterization and in vivo study. International Journal of Biological Macromolecules, 129 , 972-979. http://dx.doi.org/10.1016/j.ijbiomac.2019.02.096. PMid:30779987.

9. Abbasi, A., Emam-Djomeh, Z., Mousavi, M. A. E., \& Davoodi, D. (2014). Stability of vitamin D3 encapsulated in nanoparticles of whey protein isolate. Food Chemistry, 143, 379-383. http:// dx.doi.org/10.1016/j.foodchem.2013.08.018. PMid:24054255.

10. Luo, Y., Zeng, T., \& Wang, Q. (2012). Development of zein nanoparticles coated with carboxymethyl chitosan for encapsulation and controlled release of vitamin D3. Journal of Agricultural and Food Chemistry, 60(3), 836-843. http:// dx.doi.org/10.1021/jf204194z. PMid:22224939.

11. Chaves, M. A., Oseliero, P. L., Fo., Jange, C. G., SinigagliaCoimbra, R., Oliveira, C. L. P., \& Pinho, S. C. (2018). Structural characterization of multilamellar liposomes coencapsulating curcumin and vitamin D3. Colloids and Surfaces. A, Physicochemical and Engineering Aspects, 549 , 112-121. http://dx.doi.org/10.1016/j.colsurfa.2018.04.018.

12. Winuprasith, T., Khomein, P., Mitbumrung, W., Suphantharika, M., Nitithamyong, A., \& McClements, D. J. (2018). Encapsulation of vitamin D3 in pickering emulsions stabilized by nanofibrillated mangosteen cellulose: impact on in vitro digestion and bioaccessibility. Food Hydrocolloids, 83, 153164. http://dx.doi.org/10.1016/j.foodhyd.2018.04.047.

13. Park, S. J., Garcia, C. V., Shin, G. H., \& Kim, J. T. (2017). Development of nanostructured lipid carriers for the encapsulation and controlled release of vitamin D3. Food Chemistry, 225, 213-219. http://dx.doi.org/10.1016/j.foodchem.2017.01.015. PMid:28193417

14. Alavi, S., Haeri, A., \& Dadashzadeh, S. (2017). Utilization of chitosan-caged liposomes to push the boundaries of therapeutic delivery. Carbohydrate Polymers, 157, 991-1012. http://dx.doi. org/10.1016/j.carbpol.2016.10.063. PMid:27988018.

15. Caddeo, C., Diez-Sales, O., Pons, R., Carbone, C., Ennas, G., Puglisi, G., Fadda, A. M., \& Manconi, M. (2016). Cross-linked chitosan/liposome hybrid system for the intestinal delivery of quercetin. Journal of Colloid and Interface Science, 461, 69-78. http://dx.doi.org/10.1016/j.jcis.2015.09.013. PMid:26397912.

16. Du, H., Yang, X., \& Zhai, G. (2014). Design of chitosan-based nanoformulations for efficient intracellular release of active compounds. Nanomedicine, 9(5), 723-740. http://dx.doi. org/10.2217/nnm.14.8. PMid:24827846.

17. Alishahi, A., Mirvaghefi, A., Tehrani, M. R., Farahmand, H., Shojaosadati, S. A., Dorkoosh, F. A., \& Elsabee, M. Z. (2011). Shelf life and delivery enhancement of vitamin $C$ using chitosan nanoparticles. Food Chemistry, 126(3), 935-940. http://dx.doi. org/10.1016/j.foodchem.2010.11.086.

18. Britto, D., Moura, M. R., Aouada, F. A., Pinola, F. G., Lundstedt, L. M., Assis, O. B. G., \& Mattoso, L. H. C. (2014). Entrapment characteristics of hydrosoluble vitamins loaded into chitosan and N,N,N-trimethyl chitosan nanoparticles. Macromolecular
Research, 22(12), 1261-1267. http://dx.doi.org/10.1007/ s13233-014-2176-9.

19. Zhou, F., Xu, T., Zhao, Y. J., Song, H. X., Zhang, L. Q., Wu, X. D., \& Lu, B. Y. (2018). Chitosan-coated liposomes as delivery systems for improving the stability and oral bioavailability of acteoside. Food Hydrocolloids, 83, 17-24. http://dx.doi. org/10.1016/j.foodhyd.2018.04.040.

20. Makino, K., Yamada, T., Kimura, M., Oka, T., Ohshima, H., \& Kondo, T. (1991). Temperature- and ionic strength-induced conformational changes in the lipid head group region of liposomes as suggested by zeta potential data. Biophysical Chemistry, 41(2), 175-183. http://dx.doi.org/10.1016/03014622(91)80017-L. PMid:1773010.

21. Moore, J., \& Cerasoli, E. (2017). Particle Light Scattering Methods and Applications A2 - Lindon, John C. In G. E. Tranter \& D. W. Koppenaal (Eds.), Encyclopedia of spectroscopy and spectrometry (3rd ed., pp. 543-553). Oxford: Academic Press. http://dx.doi.org/10.1016/B978-0-12-803224-4.00040-6.

22. Gong, G., \& Bell, L. N. (2013). Degradation kinetics of rebaudioside A in various buffer solutions. International Journal of Food Science \& Technology, 48(2), 2500-2502. http://dx.doi.org/10.1111/ijfs.12241.

23. Scholfield, C. R. (1981). Composition of soybean lecithin. Journal of the American Oil Chemists' Society, 58(10), 889892. http://dx.doi.org/10.1007/BF02659652.

24. Martins, C. S., Morgado, D. L., \& Assis, O. B. G. (2016). Cashew gum-chitosan blended films: Spectral, mechanical and surface wetting evaluations. Macromolecular Research, 24(8), 691-697. http://dx.doi.org/10.1007/s13233-016-4103-8.

25. Nzai, J. M., \& Proctor, A. (1999). Soy lecithin phospholipid determination by fourier transform infrared spectroscopy and the acid digest/arseno-molybdate method: a comparative study. Journal of the American Oil Chemists'Society, 76(1), 61-66. http://dx.doi.org/10.1007/s11746-999-0048-9.

26. Tantipolphan, R., Rades, T., McQuillan, A. J., \& Medlicott, N. J. (2007). Adsorption of bovine serum albumin (BSA) onto lecithin studied by attenuated total reflectance Fourier transform infrared (ATR-FTIR) spectroscopy. International Journal of Pharmaceutics, 337(1), 40-47. http://dx.doi.org/10.1016/j. ijpharm.2006.12.021. PMid:17240095.

27. Ding, G.-J., Zhu, Y.-J., Qi, C., Lu, B.-Q., Chen, F., \& Wu, J. (2015). Porous hollow microspheres of amorphous calcium phosphate: soybean lecithin templated microwave-assisted hydrothermal synthesis and application in drug delivery. Journal of Materials Chemistry B: Materials for Biology and Medicine, 3(9), 1823-1830. http://dx.doi.org/10.1039/C4TB01862A.

28. Kiani, A., Fathi, M., \& Ghasemi, S. M. (2017). Production of novel vitamin D3 loaded lipid nanocapsules for milk fortification. International Journal of Food Properties, 20(11), 2465-2674. http://dx.doi.org/10.1080/10942912.2016.1240690.

29. Othayoth, R., Mathi, P., Bheemanapally, K., Kakarla, L., \& Botlagunta, M. (2015). Characterization of vitamin-cisplatinloaded chitosan nano-particles for chemoprevention and cancer fatigue. Journal of Microencapsulation, 32(6), 578-588. http:// dx.doi.org/10.3109/02652048.2015.1065921. PMid:26218628.

30. Martins, A. F., Oliveira, D. M., Pereira, A. G. B., Rubira, A. F., \& Muniz, E. C. (2012). Chitosan/TPP microparticles obtained by microemulsion method applied in controlled release of heparin. International Journal of Biological Macromolecules, 51(5), 1127-1133. http://dx.doi.org/10.1016/j.ijbiomac.2012.08.032. PMid:22975304.

31. Lawrie, G., Keen, I., Drew, B., Chandler-Temple, A., Rintoul, L., Fredericks, P., \& Grøndahl, L. (2007). Interactions between alginate and chitosan biopolymers characterized using FTIR and XPS. Biomacromolecules, 8(8), 2533-2541. http://dx.doi. org/10.1021/bm070014y. PMid:17591747.

Received: June 23, 2019 Revised: Aug. 09, 2019 Accepted: Oct. 01, 2019 